\title{
Students' awareness of the academic integrity policy at a Latvian university
}

\author{
Alla Anohina-Naumeca ${ }^{1 *}$ D, Ilze Birzniece ${ }^{2}$ and Tatjana Odineca ${ }^{2}$
}

\author{
* Correspondence: alla.anohina- \\ naumeca@rtu.lv \\ ${ }^{1}$ Riga Technical University, \\ Daugavgrivas Street 2-545, Riga \\ LV-1048, Latvia \\ Full list of author information is \\ available at the end of the article
}

\begin{abstract}
An academic integrity policy usually specifies the university's ethical principles and values, the forms of appropriate academic behaviour, the penalties for academic malpractice and the procedures for handling policy violations. However, the policy does not itself create academic integrity, but needs to be consistently and effectively communicated, implemented, and applied. This paper presents a case study investigating the extent to which students at Riga Technical University (Latvia) are informed about the university's academic integrity policy. This quantitative research was performed by surveying two groups of respondents: domestic students in the first year of their bachelor's studies and the heads of the corresponding study programmes. The results revealed a low level of students' awareness of the university policy on academic integrity and a lack of systematic institutional approach to promoting academic integrity. The study results also indicated that students with a higher awareness of the university policy on academic integrity were less tolerant towards violations and perceived academic integrity as an essential aspect for both the academic community and student life. These findings establish a foundation for a more extensive discussion of academic integrity issues in Latvia. They can also serve as impetus for similar studies in other Latvian universities, as well as research taking an international comparative perspective.
\end{abstract}

Keywords: Academic integrity, Higher education, Study programme, Survey, University policy

\section{Introduction}

Typically, higher education institutions care about honest, responsible and trustful conduct in academic and research activity and produce a relevant academic integrity policy as part of their core set of university policies. According to Tauginiene et al. (2018: 7-8), academic integrity refers to "compliance with ethical and professional principles, standards, practices and consistent system of values, that serves as guidance for making decisions and taking actions in education, research and scholarship". An academic integrity policy usually specifies the university's ethical principles and values, forms of appropriate academic behaviour, penalties for malpractice and procedures for handling violations. Organisational and technical means support such policies, including

(c) The Author(s). 2020 Open Access This article is licensed under a Creative Commons Attribution 4.0 International License, which permits use, sharing, adaptation, distribution and reproduction in any medium or format, as long as you give appropriate credit to the original author(s) and the source, provide a link to the Creative Commons licence, and indicate if changes were made. The images or other third party material in this article are included in the article's Creative Commons licence, unless indicated otherwise in a credit line to the material. If material is not included in the article's Creative Commons licence and your intended use is not permitted by statutory regulation or exceeds the permitted use, you will need to obtain permission directly from the copyright holder. To view a copy of this licence, visit http:/creativecommons.org/licenses/by/4.0/. The Creative Commons Public Domain Dedication waiver (http://creativecommons.org/publicdomain/zero/1.0/) applies to the data made available in this article, unless otherwise stated in a credit line to the data. 
different responsible bodies, text-matching software, reporting forms, training activities and other tools. Prenshaw et al. (2001: 204) emphasise that an academic integrity policy alters "the culture and social dynamics of the university". The critical question remains, however, of whether such policies are only declarative, or whether they are consistently and effectively communicated, implemented, and applied - in other words, whether everyday practice aligns with the policy as stated by the university.

While an academic integrity policy typically concerns all members of the university's community, students are the ones who determine, to a large extent, the reputation of the university in society. East (2009) points out that a university approach to academic integrity should be "multi-pronged and systematic": it is not enough to inform students that the policy exists - the policy must also be put into practice. This is particularly the case, as Morris and Carroll (2011) note that many students may not necessarily read and understand the policy. Currently such policies are part of a broader institutional approach that educates students about academic integrity through workshops, induction events, forums and specially developed handbooks (Devlin 2003; East 2009; MacDonald and Carroll 2006; Morris and Carroll 2011). McCabe et al. (2001) stress that it is necessary to create an "ethical community" on university campuses, where the code of conduct is firmly embedded in student culture. Prenshaw et al. (2001) emphasise that an academic integrity policy not only manages violations of academic integrity but also frames students' perceptions of such breaches. In this context, it is quite surprising that studies on student awareness of university academic integrity policies have received scant attention. Indeed, Gullifer and Tyson (2013: 1203) point out that "no research to date has actually asked students if they had read the institution's policy".

The research presented in this paper applies a case study approach to study the extent to which students of one of the largest universities in Latvia are informed about the university's academic integrity policy. This study addresses the question of student awareness of the university policy on academic integrity and adopts questions from similar research works, as well as extending the current knowledge base. This paper focuses on the relationship between student awareness level and tolerance towards violations of academic integrity, as well as students' perceptions of academic integrity as an essential aspect for both the academic community and student personal life. This research illustrates a unique aspect of academic life in Latvia, as academic integrity issues are not typically discussed widely in Latvian society.

The authors performed a quantitative study by surveying two groups of respondents: domestic students in the first year of their bachelor's studies and the heads of the corresponding study programmes. Both surveys made use of questionnaires (developed by the authors), which were delivered to respondents electronically. Student responses made it possible to identify the extent to which the students are aware about the university academic integrity policy and to establish the role awareness plays in student attitudes towards academic integrity. Surveying the study programme heads made it possible to determine whether a specific study programme used the university's general tools and mechanisms for defending academic integrity and to identify other means used for the same purpose. The authors of the paper are sure that the heads of the study programmes can influence the time and means by which institutional policies are explained and brought to the students of their study programmes. Based on the 
matching responses of both respondent groups, the authors concluded about the level of students' awareness of the university policy on academic integrity.

This paper is structured as follows: the next section provides a literature overview. Both the context of the research - the university policy and practice regarding academic integrity - and methodological approach are then specified. Further, the main findings and their interpretation are described, while conclusions are provided at the end of the paper.

\section{Literature review}

Only a few studies have focused on student awareness of university policies on academic integrity and how this awareness level shapes students' perception of and tolerance towards violations of academic integrity. Prenshaw et al. (2001) studied whether students' perception of cheating could be related to characteristics of the university policy (the level of detail, accessibility and existence of legalistic structures). McCabe's surveys, conducted in North American universities and colleges (McCabe and Treviño 1993; McCabe et al. 1996, 1999), and similar studies that adopted his approach (e.g. Florida State University 2015) asked students about the ways they are informed about the relevant academic integrity policy, and these studies provided useful insights into institution-level variables that influence students' cheating behaviour.

Bretag et al. (2014) surveyed six Australian universities $(N=15,304)$ and asked students about their awareness of academic integrity policies and their satisfaction with the way such policies were communicated to students. They found that most students were well aware of academic integrity and the relevant policies and were satisfied with the information they had received, but the researchers also highlighted the need for a broader approach incorporating effective support and training on academic integrity.

Gullifer and Tyson (2013) conducted a survey of all domestic students in one Australian university $(N=3405)$ to investigate how well the students understood plagiarism as defined in their university policy. One of their four questions is relevant to the study presented in this paper: how many students have read the policy on academic integrity? The researchers found that only half of the students had read the university's academic misconduct policy.

Academic integrity is not a common topic of research and discussion in Latvia, so there are few country-specific publications on this issue. Some of them summarise the general knowledge of well-known concepts of academic integrity (e.g. Kashkur et al. 2010), while others (e.g. Anohina et al. 2009; Anohina and Grundspenkis 2008; Grocevs and Prokofjeva 2018) discuss the development of text-matching software. Sudmale and Kulmane (2013), for example, surveyed 40 students in the first year of study at two Latvian universities to understand how students framed the concept of plagiarism. Anohina-Naumeca et al. (2018), meanwhile, studied whether the academic integrity policies in Latvian and Lithuanian public universities contained the components of an exemplary academic integrity policy. Such research has not addressed the topic of student awareness of academic integrity policies. Stabingis (2014a) partially touched upon this question and asked students whether they knew about the existence of the policies and procedures for dealing with plagiarism in their educational institution, as well as the main sources of information on avoiding plagiarism. He recommended that Latvian higher education institutions make information concerning policies on plagiarism and services for avoiding plagiarism more visible to ensure broader student use at the university (Stabingis 2014b). 
Previous studies have thus scarcely addressed the student awareness of the university policy on academic integrity and have barely considered how student awareness of the university policy on academic integrity affects student tolerance of academic integrity violations or whether students perceive academic integrity to be an essential aspect both in the academic community and in their life as a whole.

\section{Context}

Riga Technical University (RTU) is one of the largest universities in Latvia with more than 14,000 local and international students. It is the only state-funded technical university in the country. It comprises nine faculties and offers bachelor's, master's and doctoral study programmes. In the context of the paper, it is worth mentioning that the bachelor's study programmes have either an academic or vocational orientation. Academic bachelor's programmes focus on theoretical knowledge and research skills in a specific scientific domain and lead to an academic bachelor's degree. Vocational bachelor's programmes prepare students for practical activity in a specific field and include a practical placement as an obligatory part of the programme; they lead to a vocational bachelor's degree and vocational qualification.

The university ecosystem of academic integrity includes the following main components:

- understanding: providing consistent information, regulations and ethical awareness for all member groups of the academic community;

- environment: creating a professional and social environment, study conditions and role models to eliminate dishonesty;

- consequences: defining rules and taking action against academic violations; and

- technologies: introducing tools that support academic writing, text matching and systematic record keeping of academic integrity violations.

In light of these components, the university's legislation on academic integrity consists of a study agreement; a code of ethics for RTU students, academic staff and employees; the university's internal rules for students; RTU values; and the code of academic integrity. An ethics commission has also been established to consider violations of academic integrity by university students and staff.

The study agreement emphasises that each student should study honestly, should read and follow the code of ethics, should complete all assignments independently and should avoid infringing on intellectual property rights and plagiarism. The code of ethics (RTU n.d.) includes the basic principles and norms of ethical behaviour that students, academic staff and employees should follow in their attitude towards RTU, their work and relationships with other RTU representatives, as well as in private life.

The most comprehensive document is the code of academic integrity (RTU 2016), the main goal of which is to strengthen the academic culture and honesty in the university's academic environment, to clarify the concept of academic integrity and related activities and to define the main procedures used when considering violations of academic integrity. The code aims to encourage students, researchers, academic staff and employees to be loyal and fair, as well as to perform their duties honestly and responsibly, following all ethical guidelines in their work, mutual communication and personal behaviour. The code of academic integrity also defines the procedures for 
reporting, processing and appealing violations of academic integrity. It is supplemented by explanatory material on different types of plagiarism, as well as suggestions on how to deal with student violations of academic integrity, including a form specifying the type of violation and the decisions taken by the teaching staff, dean or rector. All cases of academic integrity violations are also recorded in the student's file. The university's internal rules for students emphasise that students are not allowed to use unauthorised aids in studying or to plagiarise. Possible penalties that can be applied are also included, and the highest level of penalty is expulsion from the university.

Topics regarding plagiarism prevention, academic writing, scientific ethics and information literacy are included in study programmes at all study levels and outsideclassroom events. One of the most relevant courses for this purpose is the "Introduction to Study Field" course that is a part of every study programme. This course is intended to give general information about the selected study programme and the organisation and regulations of the study process at the university. There are also workshops and conferences organised for academic staff and students.

The university encourages the implementation of engaging, student-centred study methods and practical tasks, which minimise the use of assignments of the type that typically attract plagiarism or cheating. Supporting and encouraging pedagogical improvement of the academic staff is the main goal of the recently established RTU Academic Excellence Centre. The university uses both local and internationally developed software to perform text matching of student theses, and as a result of using these tools, the faculties are updating their specific regulations to align with the desired practices and policies.

\section{Methodological approach \\ Research questions}

This study addresses the following research questions:

- What frame of reference do the study programme heads have for academic integrity?

- What experiences and practices do study programmes have for informing and educating students on academic integrity?

- What awareness do students have of the university policy on academic integrity?

- Is there a relationship between the level of student awareness of the university policy on academic integrity and their tolerance of integrity breaches?

- Is there a relationship between the level of student awareness of the university policy on academic integrity and their perception of such integrity as an essential aspect of their studies and life?

\section{Sample}

The population for this research included 47 programmes (Table 1 in Appendix) and incorporated all domestic students enrolled in the first year of their bachelor's studies on September 2018 who still had student status when the research was conducted. An overview of the sample of student participants and their demographic details are included in Table 1 (see Appendix). The students who took part in the study represented all 47 study programmes at RTU. 
The population of study programme heads included 42 individuals, 5 of whom were responsible for two study programmes with different titles. Table 1 (see Appendix) shows the sample of the study programme heads and the relevant demographic details. The study programme heads who took part in the study provided information on 22 (47\%) study programmes, representing all faculties of the university. Data on 22 study programmes were analysed to investigate the experience and practice of study programmes in the field of academic integrity. In the analyses concerning the frame of reference of the study programme heads, data from 20 respondents were processed because two heads led several study programmes at that time.

\section{Procedure and survey instruments}

Two mechanisms were used to invite students and study programme heads to take part in the research. First, a notification, an informed consent form and a link to the survey were published and made visible to the target groups in the internal university portal that is used on a daily basis. Second, the informed consent form and a link to the survey were sent out by email. The link to the student survey was valid for 12 days (15-26 November 2018); the study programme heads had access to the survey for 18 days (11-28 December 2018).

A questionnaire was developed for each target group. The student questionnaire included 21 questions total covering the following topics: familiarity with the concept of academic integrity (1 question); student awareness of the university policy on academic integrity (7 questions); student experience of academic integrity in high school (5 questions); student understanding of and attitude towards academic integrity (5 questions); and demographic details about gender, age and study programme. The questionnaire did not include sensitive questions asking whether students had ever behaved in a nonethical or dishonest way. However, this study analyses only a part of the questions that are specified in Table 2 (see Appendix).

The questionnaire intended for the study programme heads included 16 questions related to the following topics: familiarity with the concept of academic integrity (1 question); frame of reference on academic integrity (6 questions); academic integrity experience and the relevant practices of study programme (6 questions); and demographic details about gender, age and study programme. Like the student questionnaire, this paper analyses only a sub-set of the questions asked (Table 3 in Appendix).

The first question in both questionnaires addressed the respondent's familiarity with the concept of academic integrity. It was adopted from the study by Bretag et al. (2014). After this question, the same definition of academic integrity was provided to both groups to ensure a common understanding of the concept for subsequent questions.

\section{Data coding and research methods used}

Data were coded according to question type:

- single-answer multiple choice questions - the order number of the selected option;

- multiple-answer multiple choice - given the value " 1 " if an option was selected and "0" - otherwise; and

- Likert scale questions - a value from a 5-point scale ("1" represents strong agreement/acceptance and " 5 " - strong disagreement/rejection) for each question. 
Statistical analysis included the following descriptive statistics:

- (single- and multiple-answer) multiple choice questions - absolute and relative frequency; and

- Likert scale questions - absolute and relative frequency of each response for each item of the scale, mode, median (Mdn) and interquartile range (IQR).

Three combined Likert scales were defined for students. One measured the variable awareness, or how aware the student is of the university policy on academic integrity. Another scale measured the variable tolerance, or how tolerant a respondent is towards different types of academic integrity breaches. The third scale measured the variable overall academic importance - that is, the overall importance of academic integrity for the academic community. Combined scores were acquired as ranks by calculating a median for each respondent for the corresponding question (see Q_S_8, Q_S_9 and Q_S_10 in Table 2 in Appendix), as the median is a more appropriate measure of average value for ordinal data. For all combined Likert scales, Cronbach's alpha was calculated to check the internal consistency of the scale. To evaluate if students' awareness of university policy correlated with students' tolerance and perception of academic integrity as essential, a Spearman's rank-order correlation was run. The Spearman's correlation coefficient is used on ordinal data to measure the strength and the direction of association between two variables (Coolican 2014). An alpha level of .05 was set for all statistical tests, and the IBM SPSS 23.0 software package was used to analyse the survey results.

\section{Results}

\section{Programme heads on academic integrity and programme practice}

In the sample, $95 \%$ of the study programme heads $(n=19)$ indicated that they had heard of the concept of academic integrity and could explain it. Only one respondent has not heard this concept before, but he had an idea what it might mean. The same percentage indicated that students should be informed and educated about academic integrity within the study programme. Only one respondent thought the opposite.

In response to query on the most appropriate time for informing and educating students on academic integrity, $55 \%$ of the programme heads $(n=11)$ indicated that this should be done in the first semester of the bachelor's programme, $20 \%(n=4)$ thought the later semesters of the bachelor's programme and 25\% $(n=5)$ thought immediately after the beginning of studies at any educational level. Almost all respondents considered that all representatives of the university have a high level of responsibility for informing and educating students on this matter:

- university administration, faculty administration and study programme heads high $(\mathrm{Mdn}=2, \mathrm{IQR}=1)$; and

- university teaching staff - very high $(\mathrm{Mdn}=1, \mathrm{IQR}=1)$.

Most often students are informed and educated on academic integrity individually by teaching staff, during a lecture on academic integrity within the study course "Introduction to the Study Field" and during a meeting with the study programme head (see 
Fig. 1). The least popular mechanisms for the same purpose are "Workshops on academic integrity outside the study process" and "Publishing information on academic integrity on the web site of the study programme".

Students are mainly informed about text-matching software used in the university, the code of ethics and university penalties for breaches of academic integrity (see Fig. 2), although some study programmes also provide information on the Code of Academic Integrity.

In addition to information on RTU regulations, students in many programmes acquire information about types of plagiarism $(n=16 ; 73 \%)$, correct formatting of references to information sources $(n=15 ; 68 \%)$ and different styles of referencing $(n=13$; $59 \%)$. Students in about half of programmes from the sample are also informed about different types of academic integrity breaches $(n=11 ; 50 \%)$. However, information on data falsification and fabrication is only provided in some programmes $(n=7 ; 32 \%)$.

\section{Student awareness of university policies on academic integrity}

Most of the students participating in the survey had heard about the concept of academic integrity, but only $23 \%(n=211)$ of them were able to explain it. At the same time, 33\% ( $n=303)$ did not know what the concept meant. About $43 \%(n=400)$ of the students had not heard about the concept: $29 \%(n=267)$ had an idea what it meant, while $15 \%(n=133)$ had no idea about its meaning.

The students generally noticed $(n=594 ; 65 \%)$ a statement about academic integrity in their study agreement, but 35\% $(n=320)$ did not. Many students indicated that they were aware of the text-matching software used in the university (see Fig. 3). Some students had heard about the code of ethics $(n=372 ; 41 \%)$, the university penalties for a breach of academic integrity $(n=347 ; 38 \%)$, the code of academic integrity $(n=250 ; 27 \%)$ and the procedure for considering a student breach of academic integrity $(n=233 ; 25.5 \%)$. The students reported the lowest awareness of the Ethics Commission $(n=137 ; 15 \%)$ and the report form used to report a student breach of academic integrity $(n=182 ; 20 \%)$.

The students mostly reported that they knew how to access the University's internal rules for students $(n=834 ; 91 \%)$. However, only a few of the students said they knew

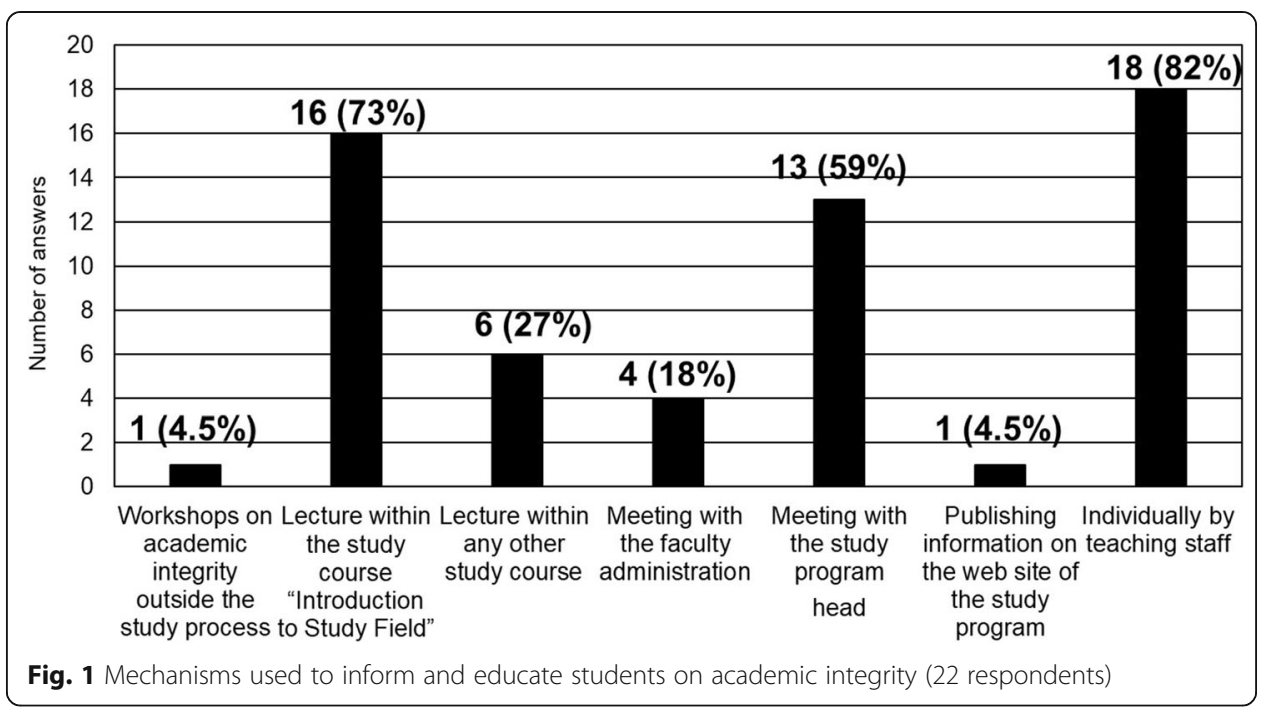




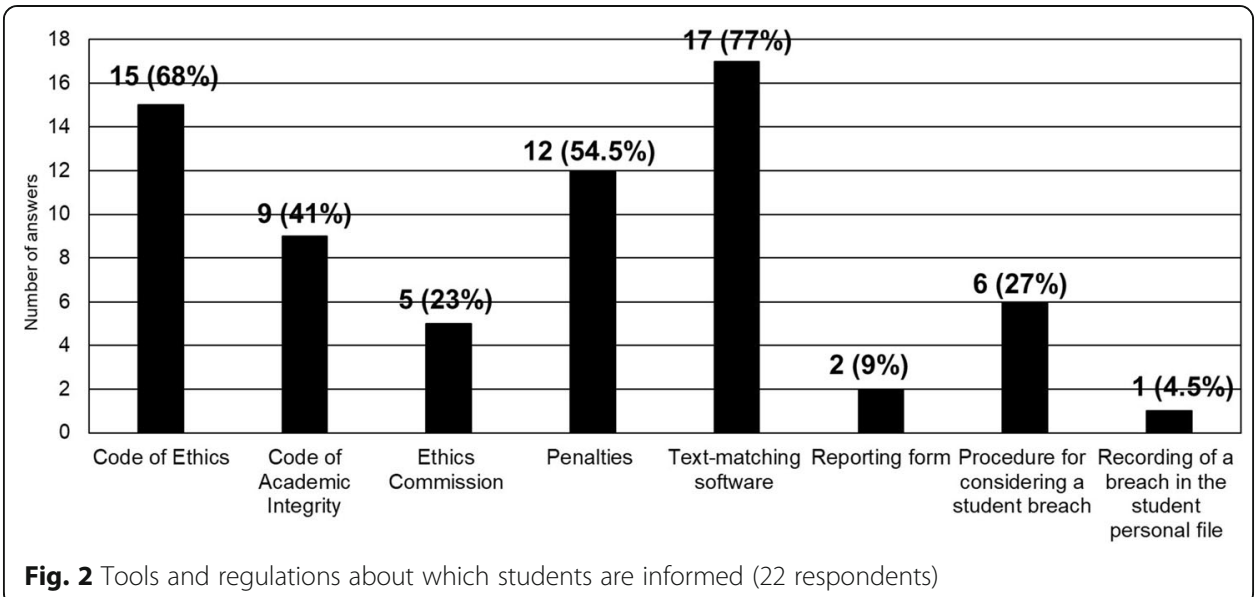

where to find other regulations on academic integrity, such as the code of ethics ( $n=$ $134 ; 15 \%)$, the code of academic integrity $(n=102 ; 11 \%)$ and the report form for a student academic integrity breach $(n=102 ; 11 \%)$. Most of the students had read at least part of the University's internal rules for students $(n=537 ; 59 \%)$. All of the other regulations, which the students did not know how to access, were mostly not read at all (more than 63\% for each regulation).

Regarding how students are informed and educated on academic integrity, the students from the sample most often selected only one option - "At least one teacher told about that in his/her study course" ( $n=345 ; 38 \%)$. The other three mechanisms that were frequently mentioned were "During a lecture on academic integrity within the study course 'Introduction to Study Field"' ( $n=286 ; 31 \%)$, "Reading the corresponding information on university/ faculty/structural unit webpage" ( $n=266 ; 29 \%)$ and "By other students" $(n=222 ; 24 \%)$. The other options were selected by less than $9 \%$ of respondents (See Fig. 4).

Slightly more than half of the students considered that a record of an academic breach in the student's file could have consequences for their further professional activity or studies $(n=471 ; 51.5 \%)$. At the same time, $41 \%(n=372)$ of the students were

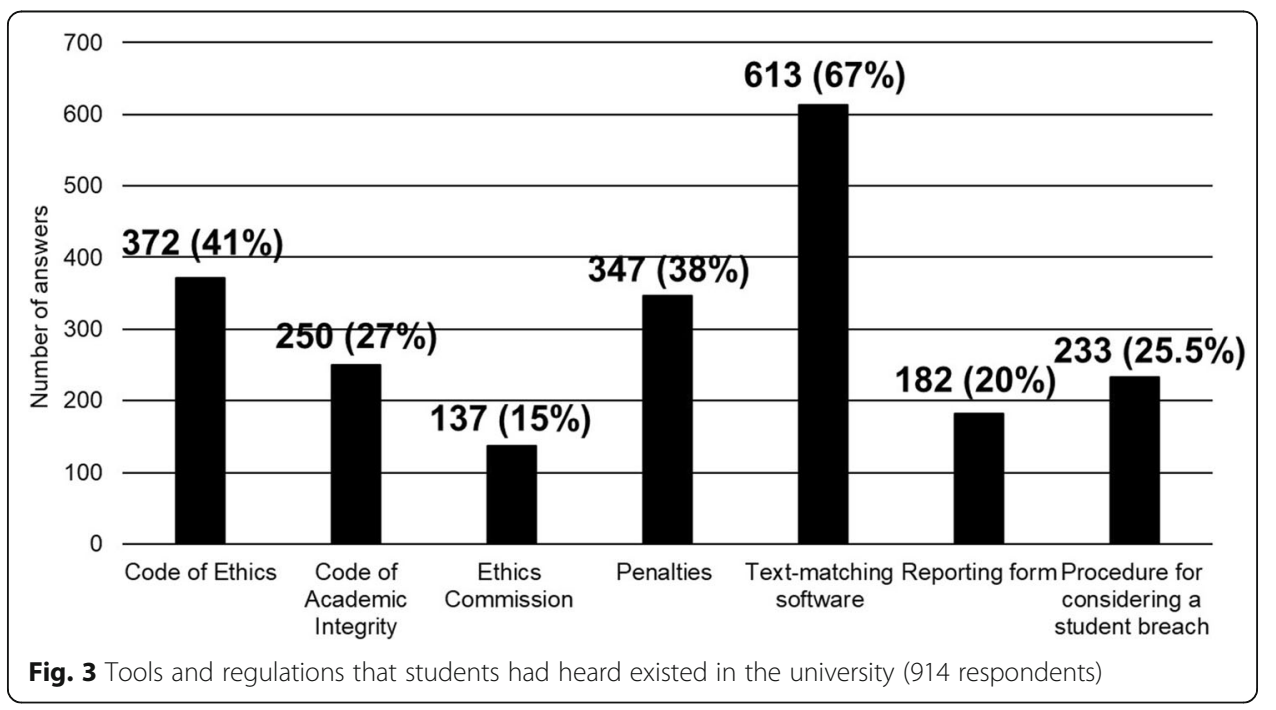




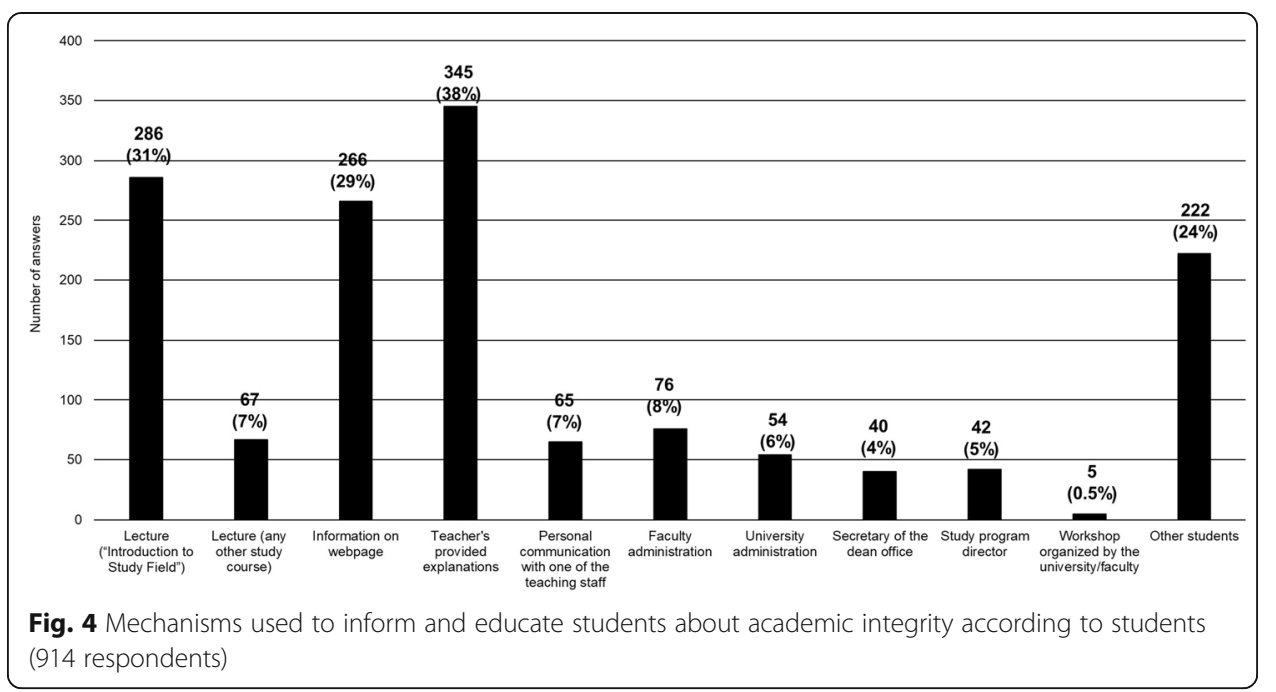

not sure about possible consequences. Only $8 \%(n=71)$ of the students from the sample indicated that they thought there would not be any consequences.

Evaluating their awareness of the university policy on academic integrity, the students were mainly neutral opinion about the extent to which they are aware of what the university considers to be an academic integrity breach $(\mathrm{Mdn}=3, \mathrm{IQR}=1)$. However, about $39 \%$ of the students agreed $(n=294 ; 32 \%)$ or strongly agreed $(n=63 ; 7 \%)$ that they are aware of this aspect. More than half of the students also indicated that they agreed (strongly or partially) that they knew how to avoid violations of academic integrity $(n=483 ; 53 \%)$, while $31 \%(n=287)$ had a neutral opinion. The students disagreed in their awareness of penalties that can be applied if a student violates academic integrity (strong or partial agreement, $n=311,34 \%$; neutral opinion, $n=325,36 \%$; strong or partial disagreement, $n=278,30 \%)$. Only $19 \%(n=176)$ of the students agreed that they knew how to appeal an academic integrity breach; $39 \%(n=359)$ had a neutral opinion and $42 \%(n=379)$ indicated disagreement.

\section{Students' understanding of and attitude towards academic integrity}

Table 4 (see Appendix) provides descriptive statistics concerning the students' perception of different types of academic integrity breaches. The highest number of students indicated that forging a teacher's signature is highly unacceptable behaviour. Many breaches (like copying the work of a classmate, signing for another student on the lecture attendance list, asking another student to complete/ write any work/task for the student, avoiding contributions to group work, falsifying data in laboratory work, putting fragments of other authors' works in the student's work without references to original sources or giving false information to a teacher or the administration) were considered unacceptable. Opinion appeared to be divided about the use of unauthorised aids for assignments: $43 \%(n=392)$ of the respondents had a neutral viewpoint. At the same time, almost the same percentage $(n=404 ; 44 \%)$ considered it unacceptable. However, the students were unable to evaluate the acceptability of some breaches - so-called "soft breaches" - because there was no direct indication of blame or participation by the student in a breach. Soft breaches included allowing a classmate to copy a student's work on any assignment, giving a student's completed work to a 
classmate, completing an individual task in cooperation with another student and remaining silent when seeing another student break the rules. There could be a very simple line of argumentation for all of such breaches, such as, "Yes, I gave my work to the classmate, but I am not responsible for how he/she used it".

The students indicated that they considered maintaining academic integrity to be important or very important for all members of the academic community (bachelor's students, master's students, $\mathrm{PhD}$ students, teaching staff, researchers and administrative staff). However, it is necessary to note that responsibility was mostly evaluated as important (not highly important) for bachelor's and master's level students, and about 21\% ( $n=$ 187) of the students did not have a definite opinion regarding bachelor's students.

Just under half of the students $(n=445 ; 49 \%)$ thought that academic integrity highly influenced or influenced their life or professional activity outside the university, 31\% $(n=284)$ had a neutral opinion and $20 \%(n=185)$ considered that it would not influence their future.

\section{Relationships among research variables}

To evaluate the relationships between the variables awareness, tolerance and overall academic importance, the Likert scales were combined and their internal consistency was evaluated using Cronbach's alpha coefficient, which showed an acceptable internal consistency $(0.768)$ for the scale measuring awareness, a very high internal consistency (0.909) for the scale measuring tolerance and good internal consistency (0.888) for the scale measuring overall academic importance. There was also a strong correlation among all items included in each scale, and it was not necessary to exclude any item from any scale based on the values for Cronbach's alpha if the item was deleted.

To evaluate the relationships among the variables mentioned above, a series of Spearman's rank-order correlation tests was run, providing the following results:

- There was a statistically significant, weak negative correlation between student awareness of the university policy on academic integrity and tolerance towards academic breaches, $\mathrm{r}_{\mathrm{s}}(912)=-.108, p<.001$.

- There was a statistically significant, weak positive correlation between student awareness of the university policy on academic integrity and the importance of academic integrity for the academic community, $\mathrm{r}_{\mathrm{s}}(912)=.123, p<.0005$.

- There was a statistically significant, weak positive correlation between student awareness of the university policy on academic integrity and the influence of academic integrity on the student's future life, $\mathrm{r}_{\mathrm{s}}(912)=.152, p<.0005$.

\section{Interpretation and discussion}

The results indicated that the study programme heads considered it necessary to inform and educate students about academic integrity, and this should be done right in the first semester of the bachelor's programme. This is relevant for the current study, but, in general, informing and educating students when they start studies at any level seems more important, because students can come from different educational institutions (from high schools for college-level studies, from other universities for master's level studies, etc.) and can have different experiences of academic integrity. Each educational institution also 
has its own policy and pattern of implementation, so students should be acquainted with the rules of the game before they start their studies at a new institution. According to the findings of Southerland-Smith (2010), who analysed several high-ranked university policies, academic integrity issues should be addressed throughout the courses offered by the faculty to raise students' awareness. The authors of the paper add that the dynamic growth of students' knowledge about academic integrity matters should correspond to the complexity of academic tasks he or she is required to complete in the curriculum.

The study programme heads shifted the greatest responsibility for informing and educating students to the teaching staff, and this also appeared in the fact that the heads mentioned university teachers as the main source of information on academic integrity. This aligns with the study by Stabingis (2014a), which revealed that in Latvian higher education institutions, students receive the main support in discouraging plagiarism from teachers. It means that the teachers should be appropriately supported from the institution and should have enough knowledge to organize the study process accordingly. This requires a targeted viewpoint to the learning process, e.g. Bertram Gallant (2017) proposes to foster a learning-oriented environment.

Most students are informed about the code of ethics, which mainly emphasises the basic principles and norms of ethical behaviour, which are an important part of university culture and policy on academic integrity. The code of academic integrity is, however, the specific regulation on academic integrity, but information about it is rarely provided. Moreover, students are provided with information on how an academic breach is identified (e.g. using text-matching software) and the penalties that are applied, but information about the process between these two events - that is, how and by whom a breach will be reported and considered - is not widely disseminated. How students could appeal such a charge is also not widely broadcast. It seems that little has changed since 2014, when Stabingis (2014b) recommended that Latvian higher education institutions should develop and make accessible procedures for handling plagiarism cases. The dangers of data falsification and fabrication in laboratory work and experiments are also rarely discussed, although these teaching methods are widely used in a technical university.

Students thus receive limited information about academic integrity, mainly from the teaching staff. This means that the university does not have a "multi-pronged and systematic" (East 2009) approach to promoting academic integrity, which the results of the student survey confirm. Slightly more than one-fifth of the students have heard about and know what academic integrity is, while the remainder have not heard about this concept and/or have no definite idea about its meaning. These findings differ significantly from the study by Bretag et al. (2014), in which most Australian students had heard about the concept of academic integrity and had a good idea what it meant. In RTU, the students mainly knew about text-matching software, the code of ethics and the penalties for violations, but they lacked information about other regulations and forms of monitoring used in the university. This aligns with the answers provided by the study programme heads and reconfirms that there is a lack of information about the parties involved in handling academic integrity violations and the nature of the relevant procedures.

More troubling is that the students did not know how to access RTU's main regulations on academic integrity and, as a result, most have not read them. The students also indicated that teaching staff were the main source of information on academic integrity, 
which is consistent with the information provided by the study programme heads. In general, the students and programme heads concurred on the lack of variety in the mechanisms used to inform students about academic integrity.

In evaluating their overall awareness of the academic integrity policy used in the university, most students indicated that they were aware of how to avoid academic violations. At the same time, there was no definite indication that the students knew what an academic integrity violation was, the penalties that would be applied and how a violation could be appealed.

The study results also showed the expected relationship between the level of student awareness of the university policy and their perception of academic integrity as an essential aspect of their academic career, as well as their level of tolerance towards academic integrity violations. This should motivate the university to contribute more to embedding ethical values in the culture of the student body.

\section{Conclusion}

The surveys presented in the paper were conducted for the first time at RTU. The results indicated the low level of student awareness of the university policy on academic integrity. The university should contribute more to the development of an institutional approach that incorporates a variety of educational and training mechanisms about academic integrity, not least because the legislative base has already been established. The findings make it possible to identify several directions for future improvement. Attention should be paid to organising workshops and awareness-raising events for all members of the university to increase awareness of the importance of academic integrity and emphasise everyone's responsibility in creating a culture of academic integrity. The established RTU Academic Excellence Centre could provide a platform for such activities.

It is also necessary to increase the number of lectures on academic integrity within the study programmes and to ensure that these cover all of the necessary regulations and procedures used within the university. The university should extend the variety of mechanisms used to support academic integrity in the university community and pay attention to students at all levels who are starting their studies at RTU. Students should be systematically educated about academic integrity violations during lectures, especially those breaches that are "less unacceptable", such as giving completed work to a classmate or completing an individual task with another student, because students were unable to evaluate the extent to which these should be deprecated. Last but not least, RTU should develop a section on academic integrity on the university webpage in both Latvian and English that would be easily accessible and contain all of the university regulations on the subject, as well as corresponding educational materials.

It is necessary to take into account the significant limitations of this research: it focused on the first few months after entering a study programme at only one Latvian higher education institution, so the results may not be generalisable to a broader context. However, the findings provide a foundation for a wider discussion about academic integrity issues in Latvia and can serve as an impetus for similar studies in other Latvian universities, as well as research from an international comparative perspective. 


\section{Appendix}

Table 1 Profile of the research sample and population

\begin{tabular}{|c|c|c|c|}
\hline & Study programmes & Students & Study programme heads \\
\hline Population & $\begin{array}{l}\text { 47: } \\
\cdot 16(34 \%) \text { - academic bachelor's } \\
\cdot 31(66 \%) \text { - vocational bachelor's }\end{array}$ & 2728 & 42 \\
\hline Sample & $\begin{array}{l}22 \text { ( } 47 \% \text { of the population): } \\
\text { - } 9 \text { ( } 41 \%) \text { - academic bachelor's } \\
\text { ( } 56 \% \text { of the population of } \\
\text { academic bachelor's study } \\
\text { programmes) } \\
\text { - } 13(59 \%) \text { - vocational bachelor's } \\
\text { (42\% of the population of } \\
\text { vocational bachelor's study } \\
\text { programmes) }\end{array}$ & $\begin{array}{l}914 \text { (33.5\% of } \\
\text { the population) }\end{array}$ & 20 (48\% of the population) \\
\hline $\begin{array}{l}\text { Demographic } \\
\text { details of the } \\
\text { sample }\end{array}$ & N/A & $\begin{array}{l}\cdot 349(38 \%) \text { - female; } \\
565(62 \%) \text { - male } \\
\text { - average age - } 22 \text { years } \\
(\mathrm{M}=21.53, \mathrm{SD}=4) ; \\
\text { minimum age } 18 \text { and } \\
\text { maximum age } 55\end{array}$ & $\begin{array}{l}\cdot 6(30 \%) \text { - female; } 14 \\
(70 \%) \text { - male } \\
\cdot \text { average age }-53 \text { years } \\
(\mathrm{M}=53.45, \mathrm{SD}=12.96) ; \\
\text { minimum age } 34 \text { and } \\
\text { maximum age } 74\end{array}$ \\
\hline
\end{tabular}

Table 2 Questions from the student survey analysed in the paper

\section{Familiarity with the concept of academic integrity}

Q_S_1: How familiar are you with the concept of academic integrity?

\section{Student awareness of the university policy on academic integrity}

Q_S_2: Did you notice a statement about academic integrity in your study agreement?

Q_S_3: Which of the items given below have you heard exist/are defined/are used in the university?

Q_S_4: Which of the items given below do you know how to access or find?

Q_S_5: How much of each of the documents mentioned below have you read?

Q_S_6: What are other ways you have been informed and educated about academic integrity since starting your studies at RTU?

Q_S_7: In your opinion, could the record of an academic breach in your student file have consequences for your further professional activity or studies?

Q_S_8: To what extent do you agree with each of the statements related to awareness of the university policy on academic integrity?

\section{Student understanding of and attitude towards academic integrity}

Q_S_9: To what extent do you accept each of the academic breaches given below?

Q_S_10: How essential is maintaining academic integrity for the various groups of the academic community?

Q_S_11: What is the extent of the impact of academic integrity on your life or professional activity outside the university?
Single-answer multiple choice (4 options)

Yes/No

Multiple-answer multiple choice (7 options)

Multiple-answer multiple choice (4 options)

Likert scale (4 items)

Multiple-answer multiple choice (12 options)

Single-answer multiple choice (3 options)

Likert scale (4 items)

Likert scale (13 items)

Likert scale (6 items)

Likert item 
Table 3 Survey questions for study programme heads analysed in the paper

Topic and questions Familiarity with the concept of academic integrity

Q_D_1: How familiar are you with the concept of academic integrity?

\section{Frame of reference on academic integrity}

Q_D_2: Do you believe that students should be informed and educated about academic integrity within the study programme?

Q_D_3: What would be the appropriate time to start informing and educating students about academic integrity?

Q_D_4: What degree of responsibility does each of the academic community groups given below have for informing and educating students about academic integrity?

\section{Study programme academic integrity experience and practice}

Q_D_5: What mechanisms are used in your study programme to inform and educate students about academic integrity during the first months of starting their studies at the bachelor's level?

Q_D_6: What are the tools and regulations that students are being informed of in your study programme during the first months of starting their studies at the bachelor's level?

Q_D_7: What additional information do students obtain in your study programme during the first months after starting their studies at the bachelor's level?

\section{Type of question}

Single-answer multiple choice (4 options)

Single-answer multiple choice (3 options)

Single-answer multiple choice (7 options)

Likert scale (4 items)

Multiple-answer multiple choice (8 options)

Multiple-answer multiple choice (8 options)

Multiple-answer multiple choice (6 options)

Table 4 Descriptive statistics for students' acceptance level of academic integrity breaches (1 strong acceptance, 5 - strong rejection)

\begin{tabular}{|c|c|c|c|c|c|c|c|c|}
\hline \multirow[t]{2}{*}{ Academic integrity breach } & \multirow[t]{2}{*}{ Mode } & \multirow[t]{2}{*}{ Mdn } & \multirow[t]{2}{*}{ IQR } & \multicolumn{5}{|c|}{ Values } \\
\hline & & & & $1(\%)$ & $2(\%)$ & $3(\%)$ & $4(\%)$ & $5(\%)$ \\
\hline $\begin{array}{l}\text { Using unauthorised aids in any assignment } \\
\text { (quiz, test or exam) }\end{array}$ & 3 & 3 & 1 & 4 & 9 & 43 & 33 & 11 \\
\hline $\begin{array}{l}\text { Copying the work of a classmate in any } \\
\text { assignment (quiz, test or exam) }\end{array}$ & 4 & 4 & 1 & 2 & 8 & 35 & 40 & 15 \\
\hline $\begin{array}{l}\text { Allowing a classmate to copy a student's work } \\
\text { in any assignment (quiz, test or exam) }\end{array}$ & 3 & 3 & 1 & 3 & 12 & 46 & 29 & 10 \\
\hline $\begin{array}{l}\text { Signing for another student in the lecture } \\
\text { attendance list }\end{array}$ & 3 & 4 & 1 & 5 & 9 & 36 & 31 & 19 \\
\hline $\begin{array}{l}\text { Giving a student's completed work to a } \\
\text { classmate }\end{array}$ & 3 & 3 & 1 & 3 & 18 & 43 & 25 & 11 \\
\hline $\begin{array}{l}\text { Asking another student to complete/write } \\
\text { any work/task for the student }\end{array}$ & 4 & 4 & 1 & 3 & 5 & 29 & 40 & 23 \\
\hline Avoiding contributing to the group work & 4 & 4 & 1 & 1 & 2 & 21 & 40 & 36 \\
\hline Falsifying data in laboratory work & 4 & 4 & 2 & 2 & 6 & 27 & 40 & 25 \\
\hline Forging a teacher's signature & 5 & 5 & 1 & 1 & 2 & 12 & 21 & 64 \\
\hline $\begin{array}{l}\text { Putting fragments of other authors' works in } \\
\text { a student's work without references to } \\
\text { original sources }\end{array}$ & 4 & 4 & 1 & 2 & 3 & 26 & 45 & 24 \\
\hline $\begin{array}{l}\text { Completing an individual task in cooperation } \\
\text { with another student }\end{array}$ & 3 & 3 & 1 & 9 & 28 & 43 & 14 & 6 \\
\hline $\begin{array}{l}\text { Remaining silent when seeing another student } \\
\text { break the rules }\end{array}$ & 3 & 3 & 0 & 7 & 15 & 59 & 14 & 5 \\
\hline $\begin{array}{l}\text { Giving false information to the teacher or } \\
\text { administration }\end{array}$ & 4 & 4 & 1 & 2 & 5 & 29 & 40 & 24 \\
\hline
\end{tabular}




\section{Abbreviation}

RTU: Riga Technical University

\section{Originality of the article}

The authors confirm that this work is original. It has not been published elsewhere and currently not submitted for publication elsewhere.

\section{Authors' contributions}

All authors contributed to the implementation of the study described in the article. The draft of the article was written mainly by the lead author. However, other authors have read, edited, and improved the article. All authors read and approved the final manuscript.

\section{Funding}

Not applicable. There are no sources of funding for the study described in the article.

\section{Availability of data and materials}

The original dataset used in the current study is available from the corresponding author on a reasonable request.

\section{Competing interests}

During the study described in the article and preparing the article, all authors were employed by the university in question. However, no one of the authors has competing interests.

\section{Author details}

${ }^{1}$ Riga Technical University, Daugavgrivas Street 2-545, Riga LV-1048, Latvia. ${ }^{2}$ Riga Technical University, Kalku Street 1-208, Riga LV-1658, Latvia.

Received: 21 July 2020 Accepted: 9 November 2020

Published online: 18 November 2020

\section{References}

Anohina A, Grundspenkis J (2008) Requirements of the plagiarism detection tool for processing template-based documents In: Proceedings of the 8th international Baltic conference on databases and information systems (Baltic DB\&lS 2008), Tallinn, Estonia, 2-5 June 2008

Anohina A, Mislevics A, Grundspenkis J (2009) Development of the plagiarism detection tool for processing template-based documents. In: Haav H-M, Kalja A (eds) Frontiers in artificial intelligence and applications, vol 187. https://doi.org/10.3233/ 978-1-58603-939-4-67

Anohina-Naumeca A, Tauginiene L, Odineca T (2018) Academic integrity policies of Baltic state-financed universities in online public spaces. Int J Educ Integr 14:1-14. https://doi.org/10.1007/s40979-018-0031-z

Bertram Gallant T (2017) Academic integrity as a teaching \& learning issue: from theory to practice. Theory Pract 56:88-94. https://doi.org/10.1080/00405841.2017.1308173

Bretag T, Mahmud S, Wallace M, Walker R, McGowan U, East J, Green M, Partridge L, James C (2014) "Teach us how to do it properly!" an Australian academic integrity student survey. Stud High Educ 39:1150-1169. https://doi.org/10.1080/ 03075079.2013 .777406

Coolican H (2014) Research methods and statistics in psychology. Psychology Press, New York

Devlin M (2003) Policy, preparation, prevention and punishment: one faculty's holistic approach to minimising plagiarism. In: Marsden H, Hicks M (eds) Educational integrity: plagiarism and other perplexities http://dro.deakin.edu.au/eserv/DU:30006 770/devlin-policypreparationprevention.pdf. Accessed 20 July 2020

East J (2009) Aligning policy and practice: an approach to integrating academic integrity. J Acad Lang Learn 3:A38-A51 https://journal.aall.org.au/index.php/jall/article/view/66. Accessed 20 July 2020

Florida State University (2015) Academic integrity survey. https://fda.fsu.edu/sites/g/files/imported/storage/original/ application/ba4467157e26476a3b47dfc6448cb24b.pdf. Accessed 5 Jan 2019

Grocevs A, Prokofjeva N (2018) Towards automated student programming homework plagiarism detection. In: Joint proceedings of the BIR 2018 short papers, workshops and doctoral consortium co-located with 17th international conference perspectives in business informatics research (BIR 2018), Stockholm, Sweden, 24-26 September 2018

Gullifer JM, Tyson GA (2013) Who has read the policy on plagiarism? Unpacking students' understanding of plagiarism. Stud High Educ 39:1202-1218. https://doi.org/10.1080/03075079.2013.777412

Kashkur M, Parshutin S, Borisov A (2010) Research into plagiarism cases and plagiarism detection methods. Sci J Riga Tech Univ 44:139-144

MacDonald R, Carroll J (2006) Plagiarism - a complex issue requiring a holistic institutional approach. Assess Eval High Educ 31:233-245. https://doi.org/10.1080/02602930500262536

McCabe DL, Treviño LK (1993) Academic dishonesty: honor codes and other contextual influences. J High Educ 64:522-538. https://doi.org/10.2307/2959991

McCabe DL, Treviño LK, Butterfield KD (1996) The influence of collegiate and corporate codes of conduct on ethics-related behavior in the workplace. Bus Ethics Q 6:461-476. https://doi.org/10.2307/3857499

McCabe DL, Treviño LK, Butterfield KD (1999) Academic integrity in honor code and non-honor code environments: a qualitative investigation. J High Educ 70:211-234. https://doi.org/10.2307/2649128

McCabe DL, Treviño LK, Butterfield KD (2001) Cheating in academic institutions: a decade of research. Ethics Behav 11:219232. https://doi.org/10.1207/S15327019EB1103_2

Morris E, Carroll J (2011) Policy works - recommendations for reviewing policy to manage unacceptable academic practice in higher education. Higher Education Academy, UK 
Prenshaw PJ, Straughan RD, Albers-Miller ND (2001) University academic dishonesty policy and student perceptions of cheating: and exploratory content analysis across fourteen universities. In: Thomas JL (ed) Advances in marketing. Association of Collegiate Marketing Educators, Jacksonville, pp 203-208

Riga Technical University (2016) The code of academic integrity (in Latvian). https://www.rtu.lv/writable/public_files/RTU_rtu_ studiju_reglaments_7.1.1.4.pdf. Accessed 22 Feb 2019

Riga Technical University (n.d.) The code of ethics (in Latvian). https://www.rtu.lv/lv/universitate/dokumenti/etikas-kodekss. Accessed 22 Feb 2019

Southerland-Smith W (2010) Retribution, deterrence and reform: the dilemmas of plagiarism management in universities. J High Educ Policy Manag 32:5-16. https://doi.org/10.1080/13600800903440519

Stabingis L (2014a) Plagiarism policies in Latvia: full report. IPPHEAE report. http://plagiarism.cz/ippheae/files/D2-3-18\%2 OLV\%20RT\%20IPPHEAE\%20ASU\%20Survey\%20Latvia.pdf. Accessed 29 June 2019

Stabingis L (2014b) Plagiarism policies in Latvia: executives summary. IPPHEAE report. http://plagiarism.cz/ippheae/files/D2-3-1 8\%20LV\%20EX\%20IPPHEAE\%20ASU\%20Survey\%20Latvia.pdf. Accessed 29 June 2019

Sudmale S, Kulmane V (2013) Education reforms in Latvia: the solution to the problem of plagiarism in computer-supported collaborative learning. Soc Res 4:128-140

Tauginienè L, Gaižauskaitè I, Glendinning I, Kravjar J, Ojstersek M, Robeiro L, Odineca T, Marino F, Cosentino M, Sivasubramaniam S, Foltynek T (2018) Glossary for academic integrity. ENAl report (revised version). http://www. academicintegrity.eu/wp/wp-content/uploads/2018/10/Glossary_revised_final.pdf. Accessed 25 Mar 2019

\section{Publisher's Note}

Springer Nature remains neutral with regard to jurisdictional claims in published maps and institutional affiliations.

- fast, convenient online submission

- thorough peer review by experienced researchers in your field

- rapid publication on acceptance

- support for research data, including large and complex data types

- gold Open Access which fosters wider collaboration and increased citations

- maximum visibility for your research: over $100 \mathrm{M}$ website views per year

At $\mathrm{BMC}$, research is always in progress. 